\title{
The association between obesity and gastrointestinal cancer
}

This article was published in the following Dove Press journal:

Gastrointestinal Cancer: Targets and Therapy

24 July 2015

Number of times this article has been viewed

\section{Claire L Donohoe \\ Suzanne L Doyle \\ John V Reynolds}

Department of Surgery, Trinity Centre for Health Sciences, Trinity College Dublin/St James's Hospital, Dublin, Ireland
Correspondence: John V Reynolds Department of Surgery,Trinity Centre for Health Sciences, Trinity College Dublin/ St James's Hospital, Dublin 8, Ireland Email reynoljv@tcd.ie

\begin{abstract}
Obesity is now recognized as one of the foremost modifiable cancer risk factors. Numerous, large-scale epidemiological studies have demonstrated that there is a clear association between the risk of cancer development at a number of sites and raised body mass index. Despite an expanding body of epidemiological evidence in support of the link between obesity and cancer, the underlying molecular mechanisms responsible are poorly characterized. Adipocytes from obese subjects exhibit an altered endocrine function and secretory profile leading to an increased release of proinflammatory molecules, resulting in a chronic low-grade inflammatory state that has been linked to the development of cancer. The level of adipokine production from adipose tissue is strongly influenced by the immune cell populations present in adipose tissue. Studies of circulating adipokine measurement are prone to bias, and although animal models have indicated some areas of promise, evidence from human studies is lacking. Cross-talk between tumor cells and adjacent adipose tissue may be an important factor in the carcinogenic process.
\end{abstract}

Keywords: obesity, gastrointestinal cancer, adipokines, insulin resistance

\section{Introduction: obesity and cancer epidemiology}

Geographic and socioeconomic differences in cancer trends and incidences indicate that environmental factors affect the development of cancer. Changes in cancer epidemiology over the last number of decades cannot be accounted for solely by changing population demographics - including increased life expectancy, increased population numbers, or improved screening, detection, and treatment leading to increased numbers of people living with a cancer diagnosis. Since not enough time has elapsed in order for significant genetic changes to account for the increased cancer incidence, it is thought that it is attributable to environmental factors. There has been an evolution in society's structure from hunter-gatherer to peasant-farmer and increasingly urbanized to industrialized. Doubtless there are have been a number of closely interrelated changes to body composition, physical activity, energy balance, and diet, and it is these environmental changes which are thought to be the cause of the alteration in cancer epidemiology.

The most compelling evidence for the association between environmental factors and cancer incidence comes from migrant studies. Migration of populations, from rural to urban environments and within and between countries has been used to show how migrant populations display changes in cancer incidence similar to their adopted country within one to two generations. ${ }^{1}$ For example, a migrant Japanese population which moved to Hawaii developed a threefold increase in breast cancer incidence in the first generation of migrants and subsequently developed up to a fivefold increase 
in the second generation. ${ }^{2}$ Similarly, the colorectal cancer incidence increased by fourfold in the first generation, but did not increase with subsequent generations, and the gastric cancer incidence, which is high in Japanese populations within Japan, decreased by almost $50 \%$ in the first generation and fell again in the second generation. Thus, these Japanese migrants developed cancer in the same pattern as their Caucasian Hawaiian neighbors than those of the same ethnicity in Japan. Similar changes among other migrant populations have been replicated in Australia, ${ }^{3}$ Canada, ${ }^{4}$ and the United States. ${ }^{5}$ Cancer incidence rates generally become similar to those of their adopted country in second generation immigrants - long before any new genetic differences could arise.

Interestingly, the increase in cancer due to environmental factors is similar in populations with clearly identifiable heritable risk factors for cancer development than those with sporadic cancers. For example, in an Icelandic population the risk of breast cancer by age 70 in BRCA- 2 carriers increased from $18.6 \%$ in 1920 to $71.9 \%$ in 2002 . This was matched by a parallel increase in the sporadic breast cancer rate, which rose from $1.8 \%$ to $7.5 \%{ }^{6}$

Excess nutrition and low physical activity can manifest itself as obesity. The prevalence of obesity has increased rapidly over the past 30 years. ${ }^{7}$ Being overweight or obese is the most prevalent body composition in some countries, for example, in the United States, where $72 \%$ of men and $67 \%$ of females are overweight or obese. ${ }^{8}$ Rates are increasing in a similar fashion in Western Europe, with $65 \%$ of men and $56 \%$ of women being overweight or obese in the United Kingdom. ${ }^{9}$ This trend shows no signs of abating as obesity rates are increasing among children, ${ }^{10}$ and overweight children tend to become overweight adults. ${ }^{11}$

In countries where sedentary lifestyles and high-energy foods are abundant, it is easy to see how energy intake exceeds that expended. It has been estimated that ingestion of $5 \%$ more calories than expended may result in an accumulation of $5 \mathrm{~kg}$ of adipose tissue in a single year. ${ }^{12}$ Humans are poorly able to distinguish foods with a high-energy content per mass, such as those high in fat and sugar, and this often leads to passive increases in calorie consumption, which is deposited as excess adipose tissue. ${ }^{13}$ In a recent analysis of the European Prospective Investigation into Cancer and Nutrition (EPIC) study, avoiding inactivity led to an equal reduction in all-cause mortality risk as did avoiding a high waist circumference, indicating that physical inactivity plays an independent role in mortality risk even in overweight patients. ${ }^{14}$
Morbidity and mortality, attributable to obesity, rise sharply with body mass index (BMI) $>30 \mathrm{~kg} / \mathrm{m}^{2},{ }^{15}$ with the risk of premature death doubling as BMI exceeds $35 \mathrm{~kg} / \mathrm{m}^{2}{ }^{2}{ }^{16}$ BMI alone is a poor measure of obesity as it may poorly reflect body composition, with raised BMIs found in patients with high muscle bulk. ${ }^{17}$ It also does not reflect differences in the site of fat distribution, and it is thought that visceral or central adiposity is more often associated with metabolic dysregulation in obesity. ${ }^{18,19}$ For a given BMI, men are at greater risk of mortality than women,${ }^{20}$ possibly relating to the increase in visceral adiposity in men versus women, which is not reflected by BMI. Conversely, energy restriction in laboratory animals has been shown to decrease spontaneous tumor occurrence in a meta-analysis. ${ }^{21}$ Mice genetically susceptible to the development of colon cancers have a reduced incidence of polyps when fed a calorie-restricted diet. ${ }^{22}$ Patients who had been hospitalized for anorexia nervosa prior to the age of 40 have been shown to have a 23\%-76\% decreased incidence of breast cancer (depending on parity). ${ }^{23}$ Thus, the optimal dietary approach to cancer risk reduction is thought to be $\mathrm{CRON}$ - calorie restriction with optimal nutrition. ${ }^{24}$

Epidemiological studies have provided convincing evidence for the association of obesity with cancer. ${ }^{25-27}$ The World Cancer Research Fund used a standardized approach in analyzing the evidence and concluded that there is convincing evidence of association between obesity and esophageal adenocarcinoma and pancreas, colorectum, breast (postmenopausal), endometrium, and kidney cancer. ${ }^{28}$

The largest meta-analysis to date includes 282,000 patients from prospective observational studies with over 133 million person-years of follow-up. ${ }^{29}$ This comprehensive analysis shows that high BMI is associated with an increased incidence of many types of cancer. The association is modest with risk estimates of $1.1-1.6$ per $5 \mathrm{~kg} / \mathrm{m}^{2}$ incremental increase in BMI. This $5 \mathrm{~kg} / \mathrm{m}^{2}$ increase in BMI corresponds to a $15 \mathrm{~kg}$ weight gain in men and $13 \mathrm{~kg}$ in women, with an average BMI of $23 \mathrm{~kg} / \mathrm{m}^{2}$.

Longitudinal epidemiological studies implicate obesity as a causal factor in the development of cancer. Further epidemiological evidence of causality comes from prospective studies of patients undergoing bariatric surgery with sustained long-term weight loss, such as those included in the Swedish Obese Subjects (SOS) study. At 10 years follow-up, the SOS study reports a reduced risk of developing cancer, which seems to be present in women alone (women: relative risk $0.58,95 \%$ confidence interval [CI] $0.44-0.77$ versus men: relative risk $0.97,95 \%$ CI $0.62-152$ ). Whether sex-specific 
or due to insufficient length of follow-up and/or sample size, it remains an area for future study. ${ }^{30}$

\section{Obesity and cancer development: causal associations}

Since obesity is now an established risk factor for cancer development, the next question is how this may be exploited in order to uncover mechanisms underpinning the link between obesity and carcinogenesis, thus opening future avenues for cancer prevention and therapy.

\section{Inflammation}

Excess adipose tissue results in elevated levels of proinflammatory adipokines, resulting in an imbalance between increased inflammatory stimuli and decreased anti-inflammatory mechanisms, leading to persistent low-grade inflammation. ${ }^{31-33}$ Adipose tissue, through the systemic alterations associated with obesity, may support the development of malignant potential in susceptible cells through supporting the other malignant processes within cancer cells, such as invasion and metastases, evasion of apoptosis, and promotion of angiogenesis and systemic inflammation. Inflammation provides the selective pressure that may drive the accumulation of mutations and results in poor immune surveillance of tumors once they develop.

Cytokines secreted by adipose tissue include the following inflammatory cytokines: TNF- $\alpha$, IL-6, IL-8, IL-10, IL-1 receptor agonist (IL-1Ra), macrophage inflammatory protein 1 (MIP-1), and monocyte chemoattractant protein 1 (MCP1). Some of these cytokines have an anti-inflammatory effect (IL-10 and IL-1Ra), but the majority are proinflammatory, and overall markers of systemic inflammation, such as C-reactive protein (CRP), are increased in the obese state. ${ }^{34}$ The increased size and number of adipocytes in adipose tissue results in areas of hypoxia within the tissue. This hypoxia induces the secretion of inflammatory factors in order to promote angiogenesis. ${ }^{35-37}$ Inflammatory cytokines attract infiltrating immune cells, which in turn produce more inflammatory cytokines. In fact, the overall level of adipokine production from adipose tissue is strongly influenced by the degree of immune cell infiltration present in adipose tissue. ${ }^{38-41}$ Adipose tissue in obese people is infiltrated with macrophages, and the number of macrophages correlates with the degree of adiposity. ${ }^{42}$

In obesity-associated systemic inflammation, there are increased circulating factors that activate the cells of the tumor microenvironment. The cells in the tumor microenvironment (including fibroblasts, neutrophils, T-cells, macrophages, and mast cells) secrete factors which support proliferation and invasion of epithelium cells, which under normal circumstances would result in wound healing, but in the presence of mutated cancer cells, promotes their further proliferation and invasion.

Animal models provide some evidence supporting these mechanisms. Obese rat models have increased inflammatory transcription factor expression (TNF- $\alpha$ and NFאB) in their tumor cells indicating activation of the tumor cells themselves to produce inflammatory cytokines which suppress the surrounding immune cells. ${ }^{43}$ Furthermore, there is emerging evidence that adipose tissue stromal cells may be a source of stromal cells in tumor microenvironments. ${ }^{44}$ Early adipocyte precursor stem cells can differentiate into stromal cells. ${ }^{45}$ In animal models of obesity, adipose stromal cells and adipose endothelial cells from inflamed visceral adipose tissue migrate to tumor sites. ${ }^{46}$ Stromal cells in the tumor microenvironment promote angiogenesis and support tumor progression. ${ }^{47}$

Levels of inflammatory cytokines, such as IL-6 and TNF- $\alpha$ seem to be associated with more advanced tumors and hence poor prognosis, ${ }^{48}$ perhaps reflecting the known association between cancer cachexia and increased inflammation. ${ }^{49}$ However, there appears to be increased serum IL-6 in patients with a colorectal adenoma. ${ }^{50,51}$ Whether IL-6 is a biomarker of inflammation or plays a causal role in cancer development is an area for future study. Preclinical studies have shown promotion of progression of colon cancer cells by IL-6, ${ }^{52,53}$ and in animals of colon cancer, IL-6 seems to enhance colon tumor growth. ${ }^{54}$

A potential confounding factor in the role of inflammation in obesity and carcinogenesis is the find that systemic inflammation is increased in patients with a diet high in fat and refined sugar. ${ }^{55}$ Adherence to a Mediterranean diet (rich in vegetables, fruit, legumes, and grains) attenuates inflammation in healthy adults. ${ }^{56}$ Studies in mice have indicated that this inflammation is mediated by changes in the gut microbiota, ${ }^{57}$ and it may be that obesity is merely a marker of this metabolic dysregulation rather than a key driver in systemic inflammation. Diet-induced weight loss decreases systemic inflammation in a randomized controlled trial of obese patients, even if the amount of weight loss (on average 5.6\%) was not enough to reverse the obese state. ${ }^{58}$

\section{Adipokine secretion}

As an endocrine organ, adipose tissue produces an array of cytoactive compounds, including the aforementioned inflammatory cytokines, with biologic functions, which 
influence metabolism. Obesity alters the amount of these proteins secreted and they may individually or collectively influence the development of cancer.

Leptin is primarily produced by white adipose tissue and acts to indicate satiety. In obesity, there is both increased production and relative resistance leading to further increases in production. It has proinflammatory and proproliferative functions. ${ }^{59}$ Serum leptin is increased in patients with obesity, but there is no clear association with circulating levels in patients and cancer risk. ${ }^{60,61} \mathrm{~A}$ polymorphism which may alter serum leptin levels, LEP G2548A, has been associated in a meta-analysis with a small increased overall cancer risk (odds ratio 1.27, 95\% CI 1.05-1.54). ${ }^{62}$ There appears to be an interplay between leptin and adiponectin, at least in experimental models of gastrointestinal cancers with downregulation of leptin-induced proliferation by adiponectin in both hepatocellular ${ }^{63}$ and esophageal carcinomas. ${ }^{64}$

Adiponectin is an abundant cytokine secreted by adipocytes in visceral fat depots, but levels are inversely associated with obesity. ${ }^{65}$ Adiponectin has antiangiogenic and antiinflammatory properties, and in animal models, it inhibits tumor growth. ${ }^{66}$ Circulating levels are reduced in patients with postmenopausal breast cancer ${ }^{67-69}$ and appear to be correlated with survival outcomes. ${ }^{70}$ Decreased expression of adiponectin is closely correlated with insulin resistance, ${ }^{71,72}$ and which mechanism is more closely correlated with carcinogenesis is unclear.

Adiponectin may also reduce expression of proinflammatory cytokines such as NFKB by reducing the growth of macrophages $^{73}$ and other proteins via AMP kinase-induced downregulation of the proproliferative mTOR pathway. ${ }^{74,75}$

In animal models, low serum adiponectin levels are associated with increased development of hepatic ${ }^{76}$ and colorectal adenomas. ${ }^{77}$ Adiponectin serum levels are inversely associated with colorectal cancer risk as shown by a meta-analysis (odds ratio $0.716,95 \%$ CI $0.606-0.847$ ), ${ }^{78}$ but this finding was not independent of either BMI or waist circumference.

\section{Hyperinsulinemia and the insulin-like growth factor axis}

One of the cardinal changes of the obese phenotype is hyperinsulinemia, and this has also been proposed as a procarcinogenic mechanism in patients with excess adipose tissue.

Insulin resistance is highly correlated with increased body weight and is reversed with weight loss. ${ }^{79}$ The mechanisms by which obesity causes insulin resistance are not fully elucidated, but it appears that inflammatory events are of central importance. Raised circulating free fatty acids, due to increased lipolysis in obese subjects, are a factor in the development of insulin resistance as they affect hepatic glucose production. ${ }^{80}$ Insulin is a mitogen and is central to the maintenance of cells in the in vitro setting. ${ }^{81}$ Epidemiological studies report a consistent association between the presence of type 2 diabetes and cancers of the liver, pancreas, endometrium, breast, colorectal, bladder, non-Hodgkin's lymphoma, and kidney. ${ }^{82}$ Confounding factors such as obesity, diet, socioeconomic status, physical activity, and smoking make it difficult to unpick how insulin resistance translates into the upregulation of cancer cell growth.

Studies to clarify this have often used supraphysiological doses of insulin to promote tumorigenesis in animal studies, ${ }^{83}$ but these doses are not clinically relevant in humans. So it is hypothesized that the coregulated and largely homologous insulin-like growth factor (IGF) system may mediate the cancer risk as activation of the IGF 1 receptor (IGF1R) leads to decreased apoptosis and increased invasiveness. ${ }^{84,85}$ Increased expression of IGF1R are reported in a number of cancer subtypes. ${ }^{86-88}$ Visceral obesity may influence the IGF1R expression in tumor tissue - in tumor samples from patients with esophageal adenocarcinoma, patients with abdominal obesity were more likely to have increased IGF1R mRNA expression and protein expression in their tumors. $^{88}$

\section{Peritumoral adipose tissue}

While there are a number of systemic alterations that occur within the obese state which may putatively impact tumor growth and metastasis, there is also cross-talk between cancer cells within a tumor and the peritumoral adipocytes. Tumor cells induced lipolysis in cancer-associated adipocytes, which induces them to undergo differentiation into fibroblast-like cells. ${ }^{63}$ These cells produced proinflammatory cytokines, which in turn support tumor cells development.

\section{Potential therapeutic avenues}

Understanding mechanisms promoting cancer development in obese patients may lead to potential development of new anticancer targets. The role of bariatric surgery in delivering sustained large-volume weight loss is well established, with most procedures leading to excess weight loss of $60 \%-70 \%$ within 2 years of surgery. ${ }^{89,90}$ Whether this translates into a reduced cancer-related mortality is not clear. As previously mentioned, the largest single study of bariatric procedures 
(the SOS study) has shown mixed results with respect to decreased cancer incidence. ${ }^{91}$ Reductions in IL-6, TNF- $\alpha$, and CRP are reported following weight loss in cohort studies. ${ }^{92}$

\section{Disclosure}

The authors report no conflicts of interest in this work.

\section{References}

1. Peto J. Cancer epidemiology in the last century and the next decade. Nature. 2001;411(6835):390-395.

2. Kolonel LN, Hinds MW, Hankin JH. Cancer patterns among migrant and native-born Japanese in Hawaii in relation to smoking, drinking and dietary habits. In: Gelboin HV, MacMohan B, Matsushima T, Sugimura T, Takayama S, Takebe H, editors. Genetic and Environmental Factors in Experimental and Human Cancer. Tokyo, Japan: Japan Science Society Press; 1980:327-340.

3. McMichael AJ, McCall MG, Hartshorne JM, et al. Patterns of gastrointestinal cancer in European migrants to Australia: the role of dietary change. Int J Cancer. 1980;25(4):431-437.

4. Yavari P, Hislop TG, Bajdik C, et al. Comparison of cancer incidence in Iran and Iranian immigrants to British Columbia, Canada. Asian Pac J Cancer Prev. 2006;7(1):86-90.

5. Flood DM, Weiss NS, Cook LS, et al. Colorectal cancer incidence in Asian migrants to the United States and their descendants. Cancer Causes Control. 2000;11(5):403-411.

6. Tryggvadottir L, Sigvaldason H, Olafsdottir GH, et al. Population-based study of changing breast cancer risk in Icelandic BRCA2 mutation carriers, 1920-2000. J Natl Cancer Inst. 2006;98(2):116-122.

7. Flegal KM, Carroll MD, Ogden CL, et al. Prevalence and trends in obesity among US adults, 1999-2008. JAMA. 2010;303(3):235-241.

8. Ogden CL, Carroll MD, Kit BK, et al. Prevalence of childhood and adult obesity in the united states, 2011-2012. JAMA. 2014;311(8):806-814.

9. Zaninotto PWH, Stamatakis E, Mindell J, Head J. Forecasting Obesity to 2010. London, UK: Department of Health; 2006.

10. Troiano RP, Flegal KM. Overweight prevalence among youth in the United States: why so many different numbers? Int J Obes Relat Metab Disord. 1999;23(Supp1 2):S22-S27.

11. Serdula MK, Ivery D, Coates RJ, et al. Do obese children become obese adults? A review of the literature. Prev Med. 1993;22(2):167-177.

12. Klein S, Wadden T, Sugerman HJ. AGA technical review on obesity. Gastroenterology. 2002;123(3):882-932.

13. Prentice AM, Jebb SA. Fast foods, energy density and obesity: a possible mechanistic link. Obes Rev. 2003;4(4):187-194.

14. Ekelund U, Ward HA, Norat T, et al. Physical activity and all-cause mortality across levels of overall and abdominal adiposity in European men and women: the European Prospective Investigation into Cancer and Nutrition Study (EPIC). Am J Clin Nutr. 2015;101(3):613-621.

15. Sjostrom LV. Morbidity of severely obese subjects. Am J Clin Nutr. 1992;55(2 Suppl):508S-515S.

16. Garrison RJ, Castelli WP. Weight and thirty-year mortality of men in the Framingham Study. Ann Intern Med. 1985;103(6):1006-1009.

17. Rothman KJ. BMI-related errors in the measurement of obesity. Int $J$ Obes. 2008;32:S56-S59.

18. Fox CS, Massaro JM, Hoffmann U, et al. Abdominal visceral and subcutaneous adipose tissue compartments association with metabolic risk factors in the Framingham Heart Study. Circulation. 2007;116(1): 39-48.

19. Fain JN, Madan AK, Hiler ML, et al. Comparison of the release of adipokines by adipose tissue, adipose tissue matrix, and adipocytes from visceral and subcutaneous abdominal adipose tissues of obese humans. Endocrinology. 2004;145(5):2273-2282.

20. Kushner RF. Body weight and mortality. Nutr Rev. 1993;51(5): $127-136$.
21. Dirx MJ, Zeegers MP, Dagnelie PC, et al. Energy restriction and the risk of spontaneous mammary tumors in mice: a meta-analysis. Int $J$ Cancer. 2003;106(5):766-770.

22. Mai V, Colbert LH, Berrigan D, et al. Calorie restriction and diet composition modulate spontaneous intestinal tumorigenesis in $\mathrm{Apc}(\mathrm{Min})$ mice through different mechanisms. Cancer Res. 2003;63(8): $1752-1755$.

23. Michels KB, Ekbom A. Caloric restriction and incidence of breast cancer. JAMA. 2004;291(10):1226-1230.

24. Hursting SD, Lavigne JA, Berrigan D, et al. Calorie restriction, aging, and cancer prevention: mechanisms of action and applicability to humans. Annu Rev Med. 2003;54:131-152.

25. Calle EE, Rodriguez C, Walker-Thurmond K, et al. Overweight, obesity, and mortality from cancer in a prospectively studied cohort of US adults. N Engl J Med. 2003;348(17):1625-1638.

26. Wolk A, Gridley G, Svensson M, et al. A prospective study of obesity and cancer risk (Sweden). Cancer Causes Control. 2001;12(1):13-21.

27. Pan SY, Johnson KC, Ugnat AM, et al. Association of obesity and cancer risk in Canada. Am J Epidemiol. 2004;159(3):259-268.

28. World Cancer Research Fund, American Institute for Cancer Research. Food, Nutrition, Physical Activity and the Prevention of Cancer: Global Perspective. Washington, DC: AICR; 2007.

29. Renehan AG, Tyson M, Egger M, et al. Body-mass index and incidence of cancer: a systematic review and meta-analysis of prospective observational studies. Lancet. 2008;371(9612):569-578.

30. Sjostrom L, Gummesson A, Sjostrom CD, et al. Effects of bariatric surgery on cancer incidence in obese patients in Sweden (Swedish Obese Subjects Study): a prospective, controlled intervention trial. Lancet Oncol. 2009;10(7):653-662.

31. Esposito K, Giugliano D. The metabolic syndrome and inflammation: association or causation? Nutr Metab Cardiovasc Dis. 2004;14:228-232.

32. Wajchenberg BL. Subcutaneous and visceral adipose tissue: their relation to the metabolic syndrome. Endocr Rev. 2000;21(6):697-738.

33. Das UN. Is obesity an inflammatory condition? Nutrition. 2001; 17(11-12):953-966.

34. Yudkin JS, Stehouwer C, Emeis J, Coppack SW. C-reactive protein in healthy subjects: associations with obesity, insulin resistance, and endothelial dysfunction a potential role for cytokines originating from adipose tissue? Arterioscler Thromb Vasc Biol. 1999;19(4): 972-978.

35. Trayhurn P, Wood IS. Adipokines: inflammation and the pleiotropic role of white adipose tissue. Br J Nutr. 2004;92(3):347-355.

36. Feldser D, Agani F, Iyer NV, et al. Reciprocal positive regulation of hypoxia-inducible factor 1alpha and insulin-like growth factor 2. Cancer Res. 1999;59(16):3915-3918.

37. Fukuda R, Hirota K, Fan F, et al. Insulin-like growth factor 1 induces hypoxia-inducible factor 1-mediated vascular endothelial growth factor expression, which is dependent on MAP kinase and phosphatidylinositol 3-kinase signaling in colon cancer cells. J Biol Chem. 2002;277(41):38205-38211.

38. Kershaw EE, Flier JS. Adipose tissue as an endocrine organ. J Clin Endocrinol Metab. 2004;89(6):2548-2556.

39. Schaffler A, Muller-Ladner U, Scholmerich J, et al. Role of adipose tissue as an inflammatory organ in human diseases. Endocr Rev. 2006; 27(5):449-467.

40. Xu H, Barnes GT, Yang Q, et al. Chronic inflammation in fat plays a crucial role in the development of obesity-related insulin resistance. J Clin Invest. 2003;112(12):1821-1830.

41. Weisberg SP, McCann D, Desai M, et al. Obesity is associated with macrophage accumulation in adipose tissue. $J$ Clin Invest. 2003;112(12):1796-1808.

42. Neels JG, Olefsky JM. Inflamed fat: what starts the fire? J Clin Invest. 2006;116(1):33-35.

43. Jain SS, Bird RP. Elevated expression of tumor necrosis factor-alpha signaling molecules in colonic tumors of Zucker obese (fa/fa) rats. Int J Cancer. 2010;127(9):2042-2050. 
44. Freese KE, Kokai L, Edwards RP, et al. Adipose-derived stems cells and their role in human cancer development, growth, progression, and metastasis: a systematic review. Cancer Res. 2015;75(7):1161-1168.

45. Rodeheffer MS, Birsoy K, Friedman JM. Identification of white adipocyte progenitor cells in vivo. Cell. 2008;135(2):240-249.

46. Zhang Y, Daquinag A, Traktuev DO, et al. White adipose tissue cells are recruited by experimental tumors and promote cancer progression in mouse models. Cancer Res. 2009;69(12):5259-5266.

47. Coussens LM, Werb Z. Inflammation and cancer. Nature. 2002; 420(6917):860-867

48. Taniguchi K, Karin M. IL-6 and related cytokines as the critical lynchpins between inflammation and cancer. Semin Immunol. 2014; 26:54-74.

49. Donohoe CL, Ryan AM, Reynolds JV. Cancer cachexia: mechanisms and clinical implications. Gastroenterol Res Pract. 2011;2011:601434.

50. Kim S, Keku TO, Martin C, et al. Circulating levels of inflammatory cytokines and risk of colorectal adenomas. Cancer Res. 2008; 68(1):323-328.

51. Sasaki Y, Takeda H, Sato T, et al. Serum interleukin-6, insulin, and HOMA-IR in male individuals with colorectal adenoma. Clin Cancer Res. 2012;18(2):392-399.

52. Becker C, Fantini MC, Schramm C, et al. TGF- $\beta$ suppresses tumor progression in colon cancer by inhibition of IL-6 trans-signaling. Immunity. 2004;21(4):491-501.

53. Becker C, Fantini M, Wirtz S, et al. IL-6 signaling promotes tumor growth in colorectal cancer. Cell Cycle. 2005;4(2):220-223.

54. Fenton JI, Birmingham JM. Adipokine regulation of colon cancer: adiponectin attenuates interleukin-6-induced colon carcinoma cell proliferation via STAT-3. Mol Carcinog. 2010;49(7):700-709.

55. Fung TT, McCullough ML, Newby P, et al. Diet-quality scores and plasma concentrations of markers of inflammation and endothelial dysfunction. Am J Clin Nutr. 2005;82(1):163-173.

56. Chrysohoou C, Panagiotakos DB, Pitsavos C, et al. Adherence to the Mediterranean diet attenuates inflammation and coagulation process in healthy adults: The Attica study. J Am Coll Cardiol. 2004;44(1): $152-158$.

57. Cani PD, Bibiloni R, Knauf C, et al. Changes in gut microbiota control metabolic endotoxemia-induced inflammation in high-fat diet-induced obesity and diabetes in mice. Diabetes. 2008;57(6):1470-1481.

58. Nicklas BJ, Ambrosius W, Messier SP, et al. Diet-induced weight loss, exercise, and chronic inflammation in older, obese adults: a randomized controlled clinical trial. Am J Clin Nutr. 2004;79(4):544-551.

59. Garofalo C, Surmacz E. Leptin and cancer. J Cell Physiol. 2006; 207(1):12-22.

60. Aleksandrova K, Boeing H, Jenab M, et al. Leptin and soluble leptin receptor in risk of colorectal cancer in the European Prospective Investigation into Cancer and Nutrition cohort. Cancer Res. 2012;72(20): $5328-5337$.

61. Wu M, Chou Y, Chou W, et al. Circulating levels of leptin, adiposity and breast cancer risk. Br J Cancer. 2009;100(4):578-582.

62. He J, Xi B, Ruiter R, et al. Association of LEP G2548A and LEPR Q223R polymorphisms with cancer susceptibility: evidence from a meta-analysis. PLoS One. 2013;8(10):e75135.

63. Park J, Morley TS, Kim M, et al. Obesity and cancer - mechanisms underlying tumour progression and recurrence. Nat Rev Endocrin. 2014; 10(8):455-465.

64. Beales IL, Garcia-Morales C, Ogunwobi OO, et al. Adiponectin inhibits leptin-induced oncogenic signalling in oesophageal cancer cells by activation of PTP1B. Mol Cell Endocrinol. 2014;382(1):150-158.

65. Kadowaki T, Yamauchi T. Adiponectin and adiponectin receptors. Endocr Rev. 2005;26(3):439-451.

66. Dalamaga M, Diakopoulos KN, Mantzoros CS. The role of adiponectin in cancer: a review of current evidence. Endocr Rev. 2012; 33(4):547-594.

67. Macis D, Guerrieri-Gonzaga A, Gandini S. Circulating adiponectin and breast cancer risk: a systematic review and meta-analysis. Int $J$ Epidemiol. 2014;43(4):1226-1236.
68. Ye J, Jia J, Dong S, et al. Circulating adiponectin levels and the risk of breast cancer: a meta-analysis. Eur J Cancer Prev. 2014;23(3): $158-165$.

69. Liu L-Y, Wang M, Ma Z-B, et al. The role of adiponectin in breast cancer: a meta-analysis. PLoS One. 2013;8(8):e73183.

70. Duggan $\mathrm{C}$, Irwin ML, Xiao L, et al. Associations of insulin resistance and adiponectin with mortality in women with breast cancer. $J$ Clin Oncol. 2011:29(1):32-39.

71. Weyer C, Funahashi T, Tanaka S, et al. Hypoadiponectinemia in obesity and type 2 diabetes: close association with insulin resistance and hyperinsulinemia. J Clin Endocrinol Metab. 2001;86(5):1930-1935.

72. Yamauchi T, Kamon J, Waki H, et al. The fat-derived hormone adiponectin reverses insulin resistance associated with both lipoatrophy and obesity. Nat Med. 2001;7(8):941-946.

73. Yokota T, Oritani K, Takahashi I, et al. Adiponectin, a new member of the family of soluble defense collagens, negatively regulates the growth of myelomonocytic progenitors and the functions of macrophages. Blood. 2000;96(5):1723-1732.

74. Barb D, Williams CJ, Neuwirth AK, et al. Adiponectin in relation to malignancies: a review of existing basic research and clinical evidence. Am J Clin Nutr. 2007;86(3):858S-866S.

75. Stofkova A. Leptin and adiponectin: from energy and metabolic dysbalance to inflammation and autoimmunity. Endocr Regul. 2009;43(4):157-168

76. Kamada Y, Matsumoto H, Tamura S, et al. Hypoadiponectinemia accelerates hepatic tumor formation in a nonalcoholic steatohepatitis mouse model. J. Hepatol. 2007;47(4):556-564.

77. Fujisawa T, Endo H, Tomimoto A, et al. Adiponectin suppresses colorectal carcinogenesis under the high-fat diet condition. Gut. 2008;57(11):1531-1538.

78. Joshi RK, Lee S-A. Obesity related adipokines and colorectal cancer: a review and meta-analysis. Asian Pac J Cancer Prev. 2014;15: $397-405$.

79. Despres JP. Is visceral obesity the cause of the metabolic syndrome? Ann Med. 2006;38(1):52-63.

80. Despres JP, Lemieux I. Abdominal obesity and metabolic syndrome. Nature. 2006;444(7121):881-887.

81. Taubes G. Unraveling the obesity-cancer connection. Science. 2012; 335(6064):28-32.

82. Johnson JA, Carstensen B, Witte D, et al. Diabetes and cancer (1): evaluating the temporal relationship between type 2 diabetes and cancer incidence. Diabetologia. 2012;55(6):1607-1618.

83. Coe PO, O'Reilly DA, Renehan AG. Excess adiposity and gastrointestinal cancer. Br J Surg. 2014;101(12):1518-1531.

84. Frasca F, Pandini G, Sciacca L, et al. The role of insulin receptors and IGF-I receptors in cancer and other diseases. Arch Physiol Biochem. 2008;114(1):23-37.

85. Samani AA, Yakar S, LeRoith D, et al. The role of the IGF system in cancer growth and metastasis: overview and recent insights. Endocr Rev. 2007;28(1):20-47.

86. Hellawell GO, Turner GD, Davies DR, et al. Expression of the type 1 insulin-like growth factor receptor is up-regulated in primary prostate cancer and commonly persists in metastatic disease. Cancer Res. 2002;62(10):2942-2950.

87. Law JH, Habibi G, Hu K, et al. Phosphorylated insulin-like growth factor-I/insulin receptor is present in all breast cancer subtypes and is related to poor survival. Cancer Res. 2008;68(24):10238-10246.

88. Donohoe CL, Doyle SL, McGarrigle S, et al. Role of the insulinlike growth factor 1 axis and visceral adiposity in oesophageal adenocarcinoma. Br J Surg. 2012;99(3):387-396.

89. Nelson DW, Blair KS, Martin MJ. Analysis of obesity-related outcomes and bariatric failure rates with the duodenal switch vs gastric bypass for morbid obesity. Arch Surg. 2012;147(9):847-854.

90. Hutter MM, Schirmer BD, Jones DB, et al. First report from the American College of Surgeons - Bariatric Surgery Center Network: laparoscopic sleeve gastrectomy has morbidity and effectiveness positioned between the band and the bypass. Ann Surg. 2011;254(3):410. 
91. Lars S, Anders G, Sjöström CD, et al. Effects of bariatric surgery on cancer incidence in obese patients in Sweden (Swedish Obese Subjects Study): a prospective, controlled intervention trial. Lancet Oncol. 2009;10(7):653-662.
92. Byers T, Sedjo RL. Does intentional weight loss reduce cancer risk? Diabetes Obes Metab. 2011;13(12):1063-1072.

\section{Publish your work in this journal}

Gastrointestinal Cancer: Targets and Therapy is an international, peer-reviewed, open access journal focusing on gastro-intestinal cancer research, identification of therapeutic targets and the optimal use of preventative and integrated treatment interventions to achieve improved outcomes, enhanced survival and quality of life for the cancer patient. The manuscript management system is completely online and includes a very quick and fair peer-review system. Visit http://www.dovepress.com/testimonials.php to read real quotes from published authors.

Submit your manuscript here: http://www.dovepress.com/gastro-intestinal-cancer-targets-and-therapy-journal 